\title{
3D model of Sin Quyen iron oxide copper deposit in Lao Cai, North Vietnam
}

\author{
Hao Duong Van ${ }^{1, *}$, Chau Nguyen Dinh ${ }^{2}$, and Wtadystaw Zygo ${ }^{2}$ \\ ${ }^{1}$ Hanoi University of Mining and Geology, Hanoi, Vietnam \\ ${ }^{2}$ AGH University of Science and Technology, Cracow, Poland
}

\begin{abstract}
The paper presents a 3D model of ore bodies of the Sin Quyen iron oxide copper-gold deposit in Lao Cai province, North Vietnam. To build 3D model we used the computer software MineScape and archival geological, geophysical data recorded from 146 boreholes, 21 tunnels and 216 trenches, including the data obtained from chemical and neutron instrumental activation analysis of 50 ore samples collected in 2015 year. The modelling process was composed of three stages: first was checking and validating of the input data, second was data processing and the last building 3D model. The model shows that the ore bodies extend below level of -300 $\mathrm{m}$, such information will be used for future exploration. Based on the obtained model, the reserves of selected metals were calculated and equal to 570000 tonnes for copper and 190 tonnes for uranium. The obtained $\mathrm{Cu}$ reserve is comparable with that estimated and published in the archival report of the Vietnam Geological Department.
\end{abstract}

Keywords: 3D modelling, Sin Quyen deposit, geophysical data, MineScape software

\section{Introduction}

One of the applications of modelling software in geology is building a 3D model of geological structure for an investigated region [1-13]. Using the 3D models the potential mineral target can be predicted and evaluating mineral resources can be performed [13-20]. The aims of the study are to build 3D geometric model of morphology, ore-bodies and to calculate the ore reserves for the iron oxide copper-gold (IOCG) Sin Quyen deposit using the archival geophysical data and the recent chemical analysis. Interpretation of the obtained model enables to gain some additional data, which will be useful for future exploration.

\section{The study area}

The Sin Quyen deposit was discovered in the 70's of the 20 century by the radiometric surveys performed under the project of Federation of Vietnam Geologists. This deposit with area of 200 ha at $22^{\circ} 37^{\prime} 20^{\prime \prime} \mathrm{N}$ latitude and $103^{\circ} 48^{\prime} 00^{\prime}$ 'E longitude is located between Fanxipan Belt

\footnotetext{
* Corresponding author: haodnth@gmail.com
} 
and Red River zones. The Fanxipan Belt is the boundary between South China block and Indochina block. This belt is dominated by Proterozoic rocks [21-22]. The Red River zone is the southeastern part of the Ailao Shan-Red River tectonic element [23, 24] (Fig. 1). According with Ta Viet Dung report [25] the Sin Quyen deposit is composed of 17 principal, steeply dipping and discontinuous ore bodies, occurring in form of lenses and veins enclosed, elongate with $100-200 \mathrm{~m}$ width, and approximately $2.5 \mathrm{~km}$ long. The copper ore bearing suite is the Proterozoic Sin Quyen metamorphosed sediment formation (SQF), which is built for amphibolites, migmatised granito - gneisses and schists trending in NW-SE direction between 280-320 degrees and dipping under 50-85 degrees [26-29]. The ore mineralization is strongly controlled by the Sin Quyen reverse fault, Pin Ngan Chai and Thung Sang faults, which are parallel to the Red River faults system in North Vietnam (Fig. 1).

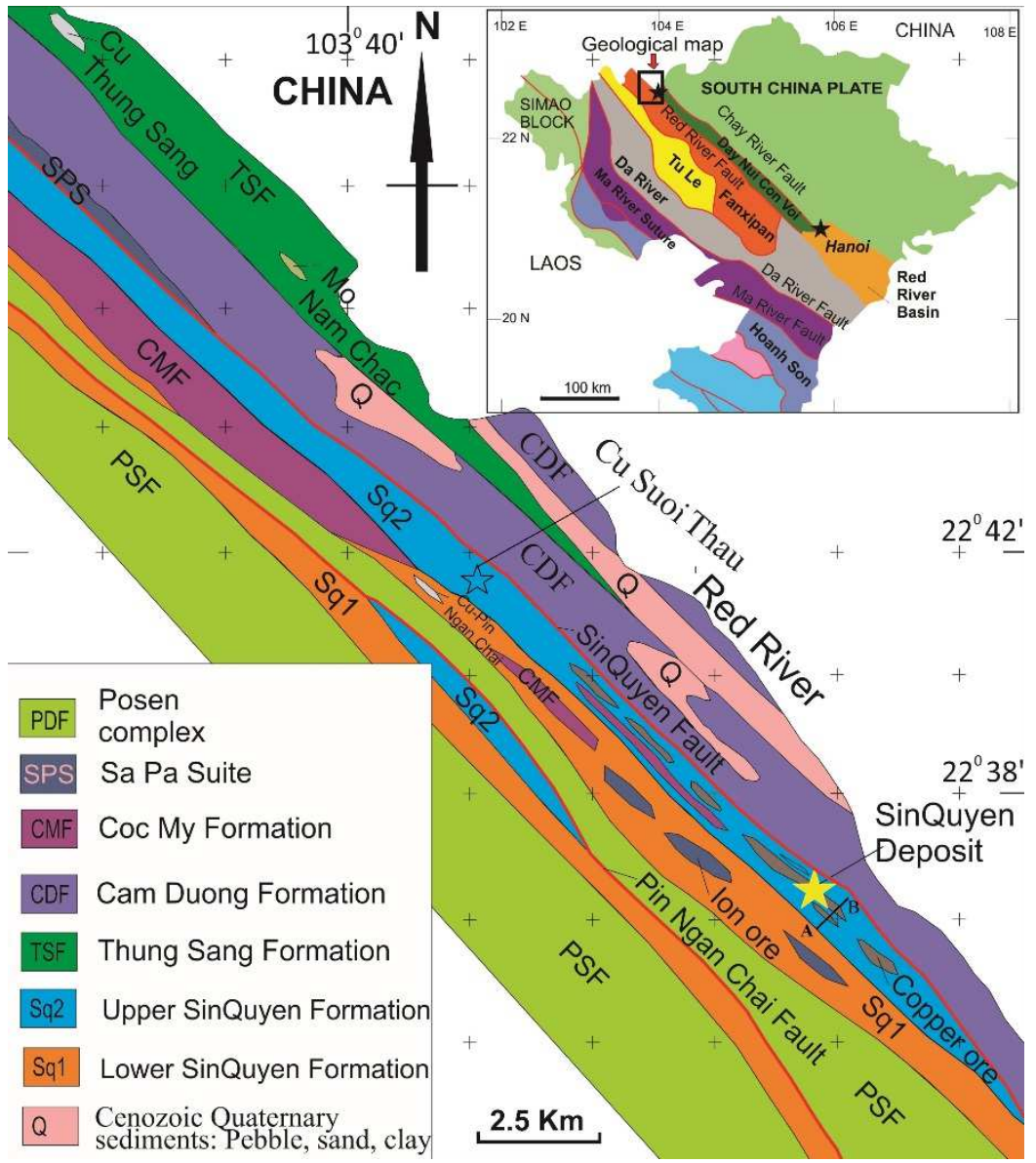

Fig. 1. The geological map of the region.

\section{3D geometric modelling}

\subsection{Data for model}

The archival data were obtained from Vietnam Geological Department under the permission "2971/ĐCKS-ĐC with 16/10/2015 of issue date". All the geophysical data and geographical coordinates (including depths) were collected from 146 boreholes, 21 underground galleries and 216 trenches distributed on the geological profiles designed over the studied deposit. The 
total measured metric lengths of boreholes, tunnels and trenches amount to 41957,7345 and $25000 \mathrm{~m}$ respectively. The authors also used geological map and the chemical results analyzed at ACME Labs (certified laboratory in Vancouver, Canada); neutron activation analysis (NAA) as well as gamma spectrometry with HPGe detector at AGH UST for 50 solid samples. The correlation between uranium and copper contents of the 50 analyzed samples is presented on figure 2 .

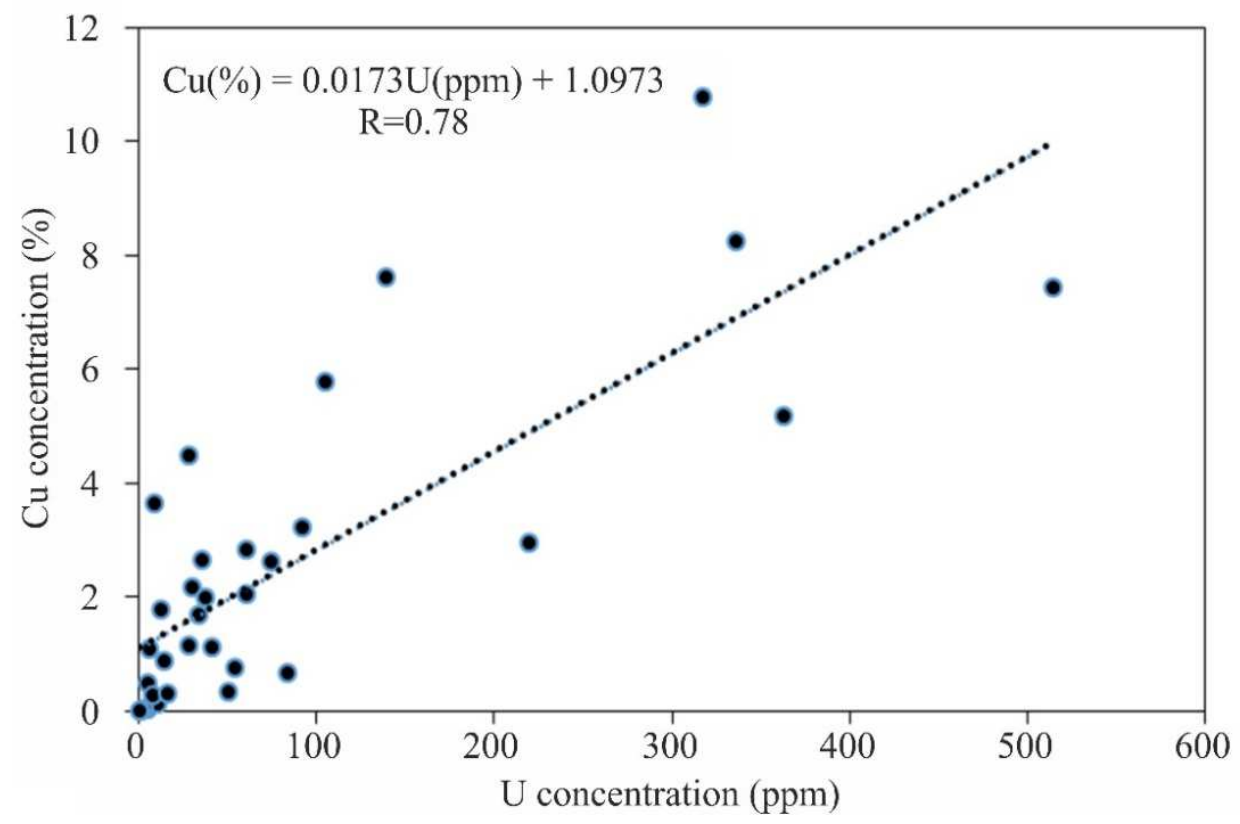

Fig. 2. The correlation between $\mathrm{U}-\mathrm{Cu}$ concentration.

\subsection{D modeling methodology}

The 3D model of the Sin Quyen deposit was built using software MineScape, product of the $\mathrm{ABB}^{\mathrm{TM}}$ Company. The scheme of the modeling process is presented on figure 3 . The modeling procedure composes of three stages. The first stage was related to inputting and validating the data. The database was transformed into the digital data, then the coordinates of boreholes, cross-sections, the geophysical data record from the galleries and trenches, borehole logs together with the geochemical and lithological data where imported into the software.

The second step was data processing. Most of the archival materials required processing and validating, and the verified data were setup as the consistent data set. 28 vertical crosssections were created based on the obtained data base. Every ore body presented on each cross-section was determined. The ore-bodies were characterized by high gamma intensity and low resistivity at the borehole logging curves (Fig. 4). Next the ore body elements on the cross-sections were identified using the characteristic geological parameters, structural direction and geophysical data. Every ore-body was drawn in an adequate polygon, which was encoded by a given ID and stored in the software. All the ID codes of the same ore body were arranged into a defined section.

The third stage comprised computation and creation of the 3D block model. The given ore body was built by the connection of the ore body's elements presented on the crosssurfaces, which are defined as the horizontal surface perpendicular to the projection of the ore bodies' trending direction on the XY surface (Fig. 5). 
The new geochemical data together with the drill core analyzed results and lithology information were used as the input. The data were processed, correlated and interpreted.

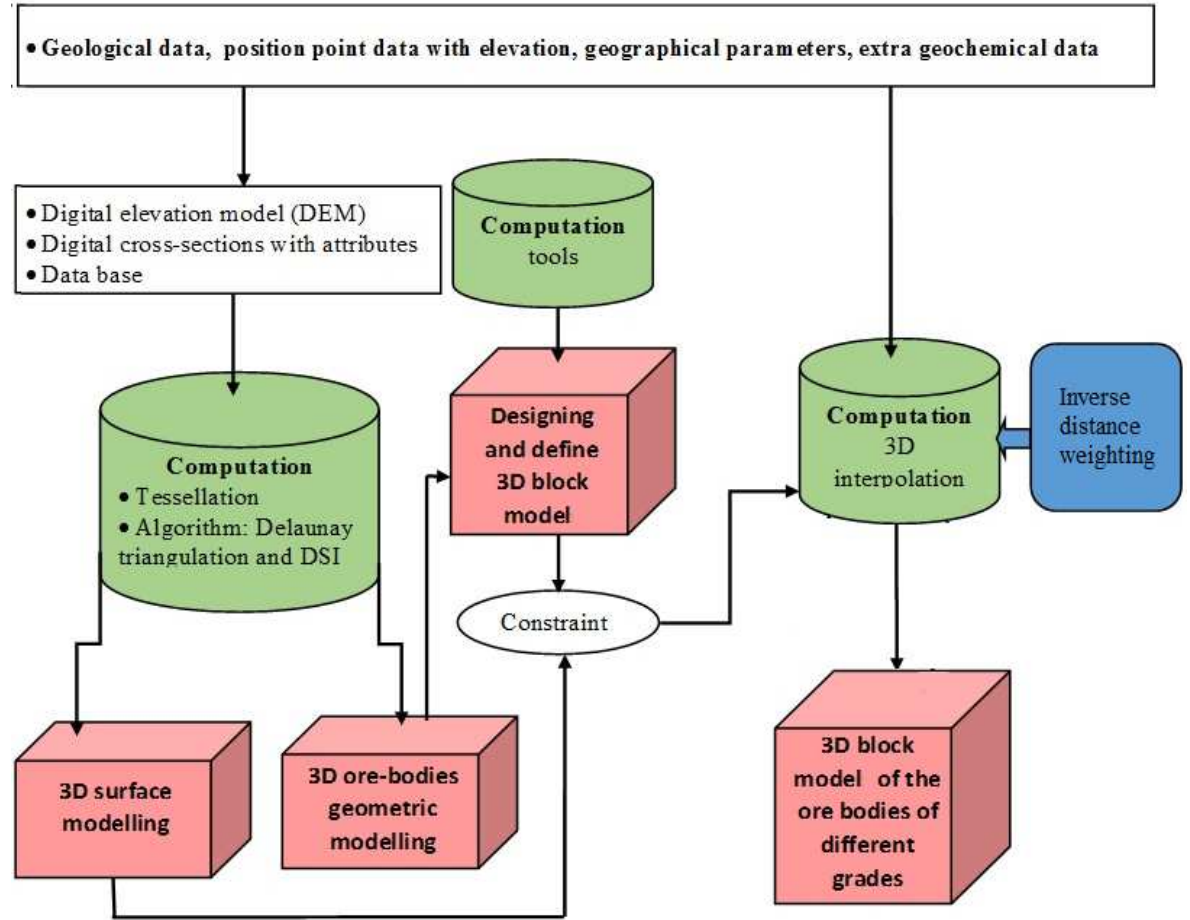

Fig. 3. The block scheme of 3D modeling process.

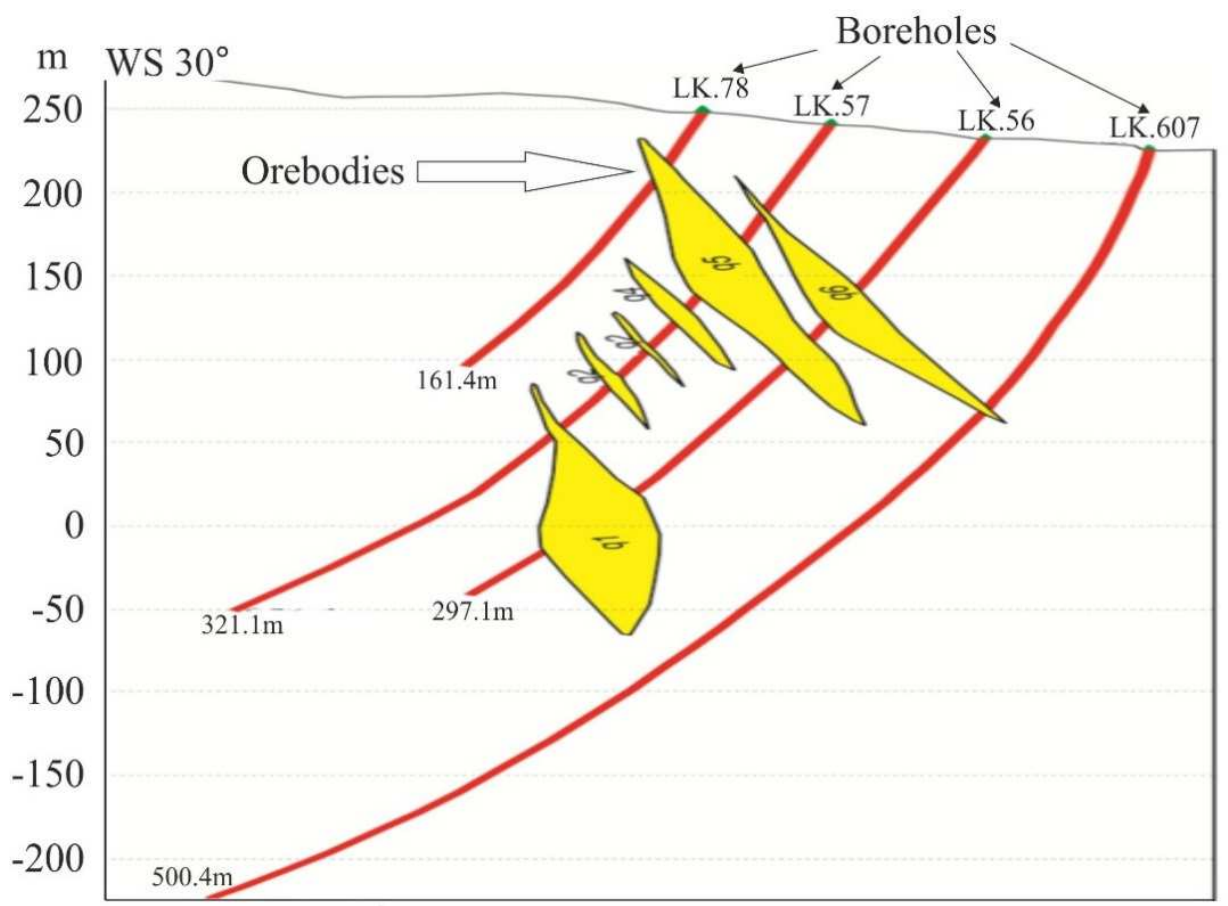

Fig. 5. Creating wireframes of the ore bodies based on borehole geophysics and structural data. 


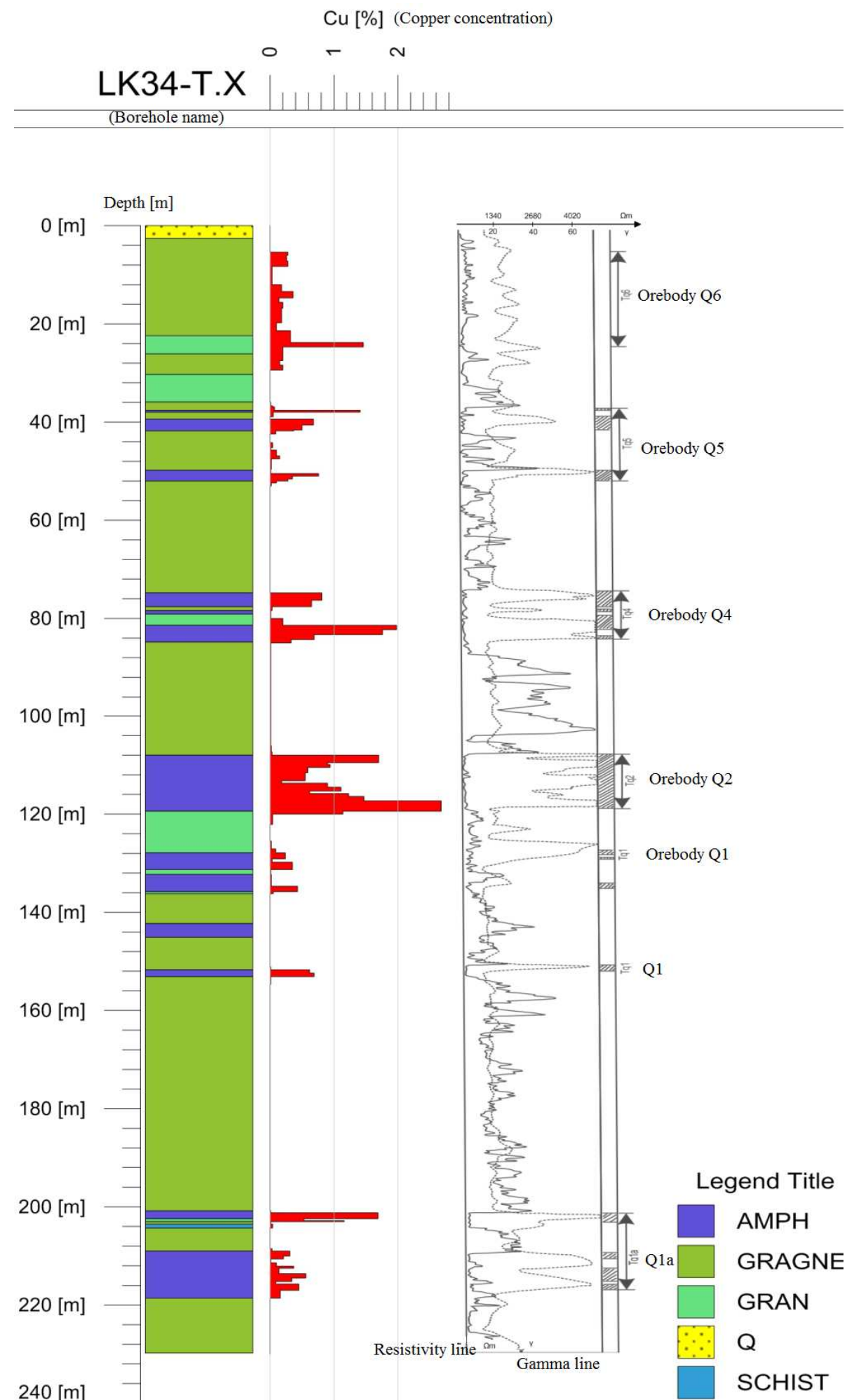

Fig. 4. The ore-bodies and $\mathrm{Cu}$ grades determined using natural gamma and resistivity curves. 
The obtained results such as the fit curves, the geochemical behaviors of $\mathrm{U}$ and $\mathrm{Cu}$ elements and their distributions emerged from the interpretation. They served together with the coordinates of the well-known analyzed points as the data used to interpolate the points, where there was a lack of the analyzed data. The block model was created only inside wireframes prepared for all ore bodies. The interpolation was performed using inverse distance weighting, which background will be compendiously described in the next paragraph.

\subsection{Interpolation}

\subsubsection{Inverse Distance Weighting (IDW)}

Based on distribution of samples and software predispositions for grade interpolation nongeostatistical (classical) method was chosen. One of the classical interpolation methods is inverse distance weighting, in which each sample is weighted according to some power of the inverse of its distance from the block to be estimated. In the IDW interpolation the search neighborhood controls both the selection of input points and the amount of weighting given to each point. In this method the search ellipsoid needs to be defined. The search ellipsoid and its parameters controls the process of interpolation. In the block model copper content was interpolated. Before this process samples were flagged to its own wireframes. This step prevents from mixing samples between different ore-bodies. The radius for the search ellipsoid was set on $200 \mathrm{~m}$. After the interpolation, the obtained block model was validated. The set of temporary sections through the block model was created and validated against samples from drill holes.

\subsubsection{Discrete Smooth Interpolation (DSI)}

The discrete smooth interpolation was used for estimation of the unknown nodes based on the known nodes on the network [30]. The known and unknown nodes are on a common network mesh of a given discrete geological object (e.g. a triangulated surface). The DSI is used to compute the location coordinates (elevation) of nodes and to measure the total "roughness" of various interpolating solutions using a specialized quadratic criterion. It allows also selection of the solution showing the least roughness [31]. At the each node the roughness is defined as the square of the difference between its elevation and the weighted average elevation of the neighbor nodes in the mesh. The DSI method is the useful approach, which is a weighted sum of a local geometrical roughness and the violation degree of the constraints used to this object.

\subsubsection{Delaunay Triangulation}

The Delaunay triangulation is used to build a model of the terrain surface elevations, which can start with a number of sample points of known height. The Delaunay triangulation always attempts to maximize the amount of acute angle of the triangles in the triangulation. In particular, the Delaunay triangulation avoids sliver triangles. By this way the estimation can reach the highest precision.

\subsection{The 3D surface model}

The 3D surface modeling is built to back up the initial natural pattern of topography. The model shows elevated levels and all ore outcrops in the initial area. The surface modelling 
demonstrates various factors such as: topography, ore-body outcrops and boreholes localization (Fig. 6). In the Sin Quyen deposit the surface model indicates the outcrop of the copper ore bodies in the terrain along NW-SE strikes, which is rougher in comparison with the surrounding zones. In the depression center there is Ngoi Phat water stream formed by the geological faults trending on the northeast direction under 30-40 degrees of azimuth. The boreholes with core samples mark in yellow color are also presented on figure 6 .

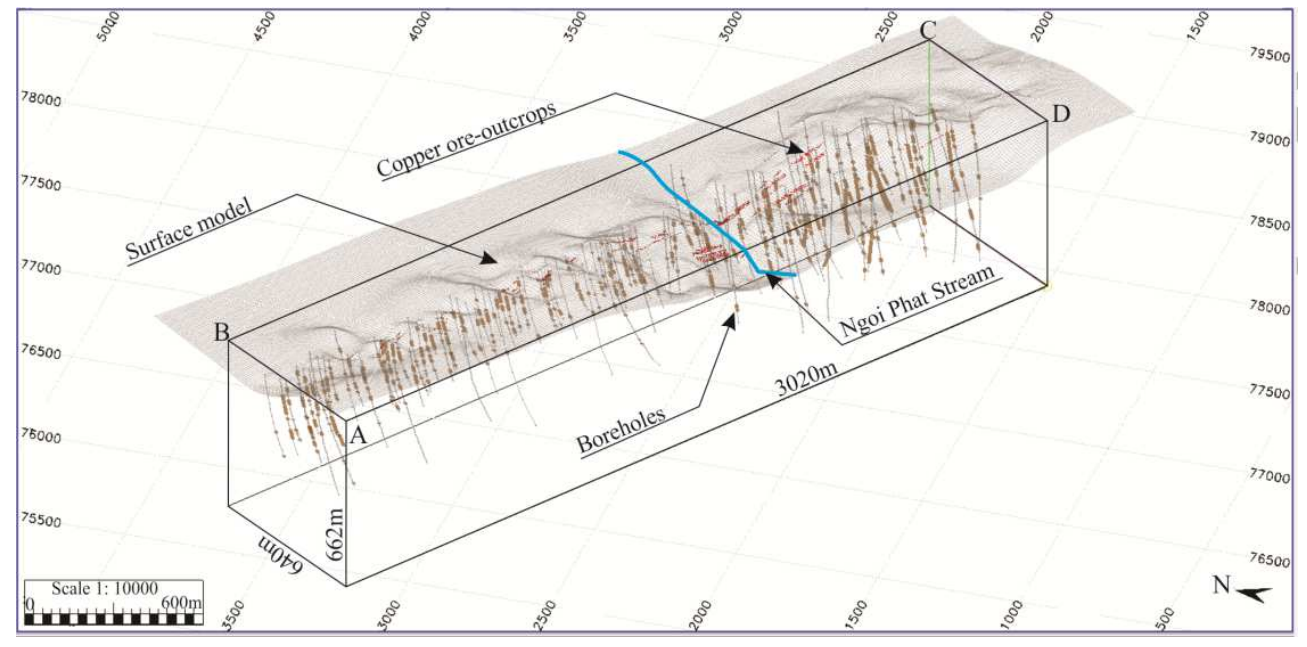

Fig. 6. The surface model of the studied area.

\subsection{The 3D model of ore-bodies}

The figure 7 presents the modeled projections of all ore bodies on the surface XY. Each ore body was built based on the connection of its fragments in the different boreholes. The fragments belong to an ore-body are characterized by the similar geophysical properties, related rock formation, and the coordinates of the ore-body. In order to present more clearly every ore body was marked with different color.

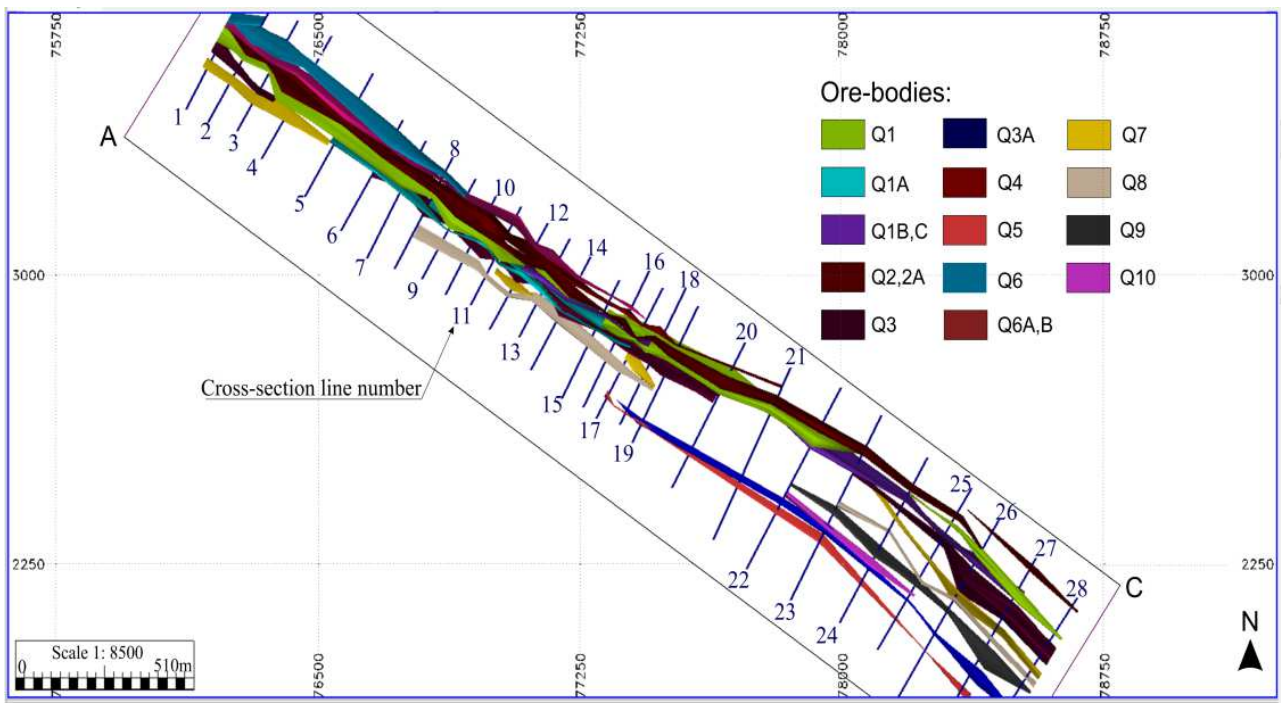

Fig. 7. The projection of the all bodies on the surface XY. 
Based on the relation of $\mathrm{U}-\mathrm{Cu}$, the model of the distribution of different grades of $\mathrm{Cu}$ metal was built (Fig. 8).

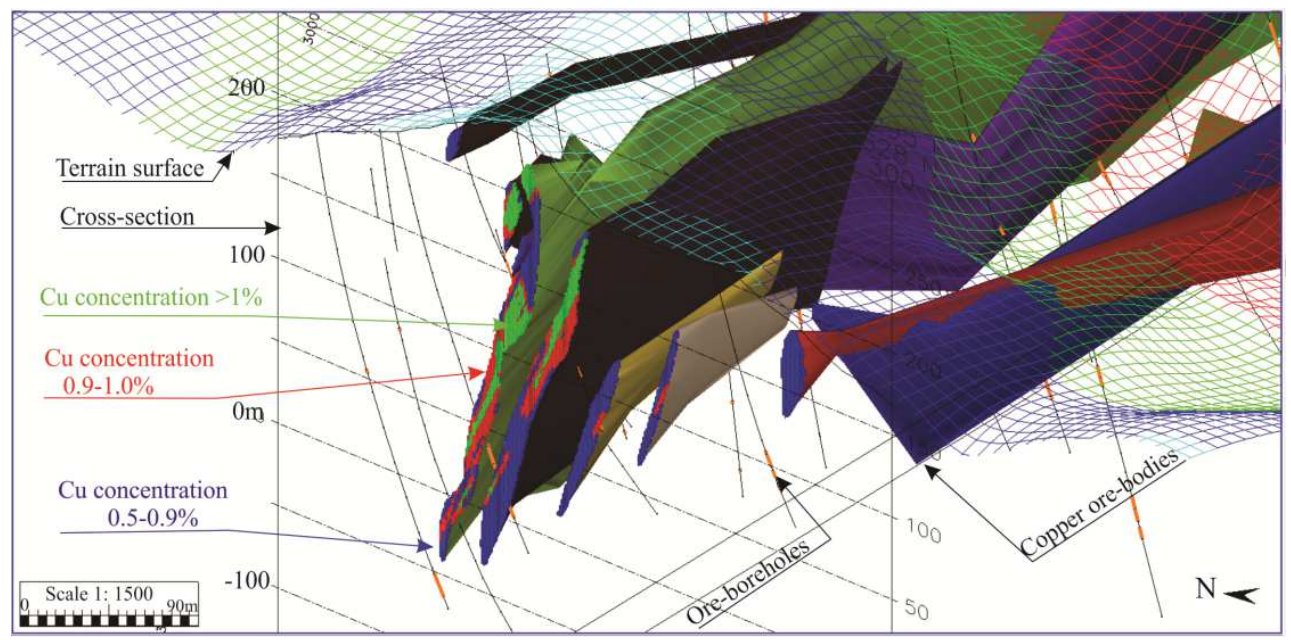

Fig. 8. View out of the slice of ore bodies with different grades.

\subsection{Resources}

Based on the block model, the $\mathrm{Cu}$ and $\mathrm{U}$ resources elements were estimated and amounted to 569600 tons and 190 tons respectively. The calculated $\mathrm{Cu}$ resources are comparable with that given in the report prepared by Ta Viet Dung [29].

\section{Conclusions}

The chemical and geophysical data were useful to estimate the correlation and determine the geometrical parameters of the ore-bodies. Using the computer software MineScape 5.12 the $3 \mathrm{D}$ models of ore bodies were built. The 3D models enable to estimate the resources of $\mathrm{Cu}$ and other accompanying metals. The obtained 3D model enables us to follow not only the shape of ore-bodies but also the metal grade distribution in the study deposit. The accuracy of the $3 \mathrm{D}$ modeling is strongly depends on the conception model, used algorithms and the input data.

\section{Reference}

1. J. P. Chiles, C. Aug, A. Guillen, T. Lees, Proceedings of International Symposium on Orebody Modelling and Strategic Mine Planning, Perth, Australia, 22-24 November 2004. 313-320 (2004)

2. E. Rodrigues Duran, R. Di Primio, Z. Anka, D. Stoddart, B. Horsfield, Mar. Petrol. Geol. 45, 281-303 (2013) doi: 10.1016/j.orggeochem.2013.07.011

3. C. Fei, L. Jiangping, W. Jing, Z. Yuquan, Y. Mingyu, J. Appl. Geophys. 134, 246-252 (2016)

4. Z. Guo, L. Sun, A. Jia, T. Lu, Petrol. Explor. Dev+ 42, 83-91 (2015) doi: 10.1016/S1876-3804(15)60009-X

5. A.S. Høyer, F. Jørgensen, P.B.E. Sandersen, A. Viezzoli, I. Møller, J. Appl. Geophys. 122, 94-102 (2015) doi: 1016/j.jappgeo.2015.09.004 
6. J.L. Mari, B. Yven, Mar. Petrol. Geol.. 53, 133-153 (2014) doi: 10.1016/j.marpetgeo.2013.10.014

7. M. Perrin, B. Zhu, J.F. Rainaud, S. Schneider, J. of Petrol. Sci. Eng. 47, 89-104 (2005) doi: 10.1016/j.petrol.2004.11.010

8. S. H.H. Nielsen, F. Cunningham, R. Hay, G. Partington, M. Stokes, Ore Geol. Rev. 71, 578-591 (2015) doi: 10.1016/j.oregeorev.2015.02.001

9. N.M. Sirakov, F.H. Muge, Comput. Geosci. 27, 59-69 (2001) doi: 10.1016/S00983004(00)00055-8

10. J. Wu, Y. Sun, B. Wang, Y. Wang, L. Xu, C. Dai, Petrol. Explor. Dev+. 39, 99-106 (2012) doi: 10.1016/S1876-3804(12)60020-2

11. Y.Y. Zhang, D.J.. Liu, G.H. Ai, M.J,Qin. J. Appl. Geophys.. 109, 292-300 (2014) doi: 0.1016/j.jappgeo.2014.08.011

12. A.T. Zehnder, R.W. Allmendinger, J. .Struct. Geol.. 22, 1009-1014 (2000) doi: 10.1016/S0191-8141(00)00037-7

13. A.M. Lemon, N.L. Jones, Comput. Geosci. 29, 547-555 (2003) doi: 10.1016/S00983004(03)00051-7

14. P. Calcagno, G. Courrioux, A. Guillen, J.P. Chiles, Phys. Earth Planet. In. 171, 147-157 (2008) doi: 10.1016/j.pepi.2008.06.013

15. G. Wang, S. Zhang, C. Yan, Y. Song, Y. Sun, D. Lo, F. Xu, Comput. Geosci. 37, 19761988 (2011) doi: 10.1016/j.cageo.2011.05.007

16. P. Gumiel, M. Arias, A. Martín-Izard, Geol. J. 45, 623-633 (2010) doi: 10.1002/gj.1192

17. A. Martin-Izard, D. Arias, M. Arias, P. Gumiel, D.J. Sanderson, C. Castañon, A. Lavandeira, J. Sanchez, Ore Geol. Rev. 71, 457-476 (2015) doi: 10.1016/j.oregeorev.2015.06.006

18. M. Maxelon, P. Renard, G. Courrioux, M. Brandli, N. Mancktelow, Comput. Geosci. 35, 644-658 (2009) doi: 10.1016/j.cageo.2008.06.005

19. O. Kaufmann, T. Martin, Comput. Geosci. 34, 278-290 (2008) doi: 10.1016/j.cageo.2007.09.005

20. G. Wang, R. Li, E.J.M. Carranza, S. Zhang, C. Yan, Y. Zhu, J. Qu, D. Hong, Y. Song, J. Han, Z. Ma, H. Zhang, F. Yang, Ore Geol. Rev. 71, 592-610 (2015) doi: 10.1016/j.oregeorev.2015.03.002

21. P.T. Hieu, F.K. Chen, N.T.B. Thuy, C.N. Quoc, S.Q. Li, J. Geodyn. 69, 106-121 (2013) doi: 10.1016/j.oregeorev.2015.03.002

22. P.H. Leloup, R. Lacassin, P. Tapponnier, U. Scharer, D. Zhong, X. Liu, L. Zhang, S. Ji, T.T. Phan, Tectonophysics. 251, 3-84 (1995) doi: 10.1016/0040-1951(95)00070-4

23. H. H. Huang, Z.J. Xu, Y.M. Wu, X. Song, B.S. Huang, L.M. Nguyen, Tectonophysics. 584, 230-239 (2013) doi: 10.1016/j.tecto.2012.03.030

24. P. Tapponnier, R. Lacassin, P.H. Leloup, U. Schuarer, D. Zhong, H. Wu, X. Liu, S. Ji, L. Zhang, J. Zhong, Nature. 343, 431-437 (1990) doi: 10.1038/343431a0

25. T. V. Dung, Report of geological surveys and their results performed at the IOCG Sin Quyen deposit in Lao Cai, North Vietnam. Main Department of Geology of Vietnam, 318 p. (1975) (in Vietnamese)

26. S. Ishihara, H. Hideo, H. Mihoko, P.N. Can, T.D. Pham, T.A. Tran, Bulletin of the Geological Survey of Japan. 62, 197 - 209 (2011)

27. R.N. McLean, PGC Publishing, Adelaide. 2, 293-301 (2001) 
28. J. Pieczonka, A. Piestrzyński, L.K. Phon ., N.D.Chau, P. Jodłowski, Viet-Pol 2015 second international conference on scientific research cooperation between Vietnam and Poland in Earth Sciences. 331-353 (2015)

29. I.V. Gaskov, T.A. T.T. Hoa. Tran, T.D. Pham, P.A. Nevolko, N.C, Pham, Russ. Geol. Geophys + . 53, 442-456 (2012)

30. J.L. Mallet, Comput. Aided Des. 24, 178-191 (1992) Doi: 10.1016/00104485(92)90054-E

31. J.L. Mallet, Math. Geol. 29, 199-219 (1997) doi: 10.1007/BF02769628C. Le Carlier de Veslud, M. Cuney, G. Lorilleux, J.J. Royer, M. Jebrak, Comput. Geosci. 35, 92-107 (2009) doi: 10.1016/j.cageo.2007.09.008 